CASE REPORT

\title{
Hypercalcaemia in infancy; a presenting feature of spinal muscular atrophy
}

\author{
K Khawaja, W T Houlsby, S Watson, K Bushby, T Cheetham
}

Arch Dis Child 2004;89:384-385. doi: 10.1136/adc.2003.028225

A 10 month old girl presented with a history of constipation from early life. She was found to be hypercalcaemic with hypercalciuria and nephrocalcinosis. Her mild motor delay and hypotonia were thought to be linked to chronic hypercalcaemia, but when these features failed to improve despite normocalcaemia on a low calcium diet the possibility of neuromuscular disease was explored in more detail. She was subsequently found to have spinal muscular atrophy type 2. We suspect that the hypercalcaemia with hypercalciuria observed in this case reflects altered bone turnover secondary to reduced muscular activity.

$\mathrm{H}$ percalcaemia is an uncommon problem in infancy. It may be a manifestation of Williams' syndrome, vitamin $\mathrm{D}$ or calcium excess, as well as disorders associated with reduced bone formation, such as hypophosphatasia, or increased bone resorption, such as malignancy. ${ }^{1}$ Occasionally it may reflect an abnormality of the calcium sensing receptor (hypocalciuric hypercalcaemia) with an associated altered "set point". ${ }^{2}$ Primary hyperparathyroidism is extremely rare in infancy. ${ }^{3}$ We present a case of spinal muscular atrophy type 2 where the initial presentation was with hypercalcaemia and constipation. Recognised causes of hypercalcaemia in infancy were excluded and we suspect that the raised calcium reflects altered bone turnover secondary to the underlying neuromuscular disease.

\section{CASE REPORT}

A 10 month old girl presented with a long standing history of constipation. She was born at 41 weeks gestation following an unremarkable pregnancy. She passed meconium within the first 24 hours but became constipated shortly afterwards and for many months was only opening her bowels every 1014 days. She was referred to the local hospital and was awaiting review by the paediatric surgeons with a view to performing a rectal biopsy, when she was found to be hypercalcaemic $(3.16 \mathrm{mmol} / \mathrm{l}$ and $3.21 \mathrm{mmol} / \mathrm{l})$ with a suppressed parathyroid hormone (PTH) (5 ng/l; normal range $10-65 \mathrm{ng} / \mathrm{l}$ ).

On examination she had a relatively flat nasal bridge and blue eyes. She was hypotonic but there were no other abnormal findings at that stage. Her head circumference was on the 50th centile with a length and weight around the 9th centile at the time of presentation.

William's syndrome was suspected initially but FISH analysis looking for deletion of the elastin gene on chromosome $7^{4}$ was negative. She had evidence of nephrocalcinosis on a renal ultrasound scan and her urine calcium creatinine ratio was relatively high at $3.2 \mathrm{mmol} / \mathrm{mmol}$. Her alkaline phosphatase (ALP) was low with a level of 93 IU/1 (150$380 \mathrm{IU} / \mathrm{l})$ and although the diagnosis of hypophosphatasia was considered, she did not have the typical clinical features of the infantile form such as blue sclerae, a widely open fontanelle, and skeletal deformity. Chest and wrist radiographs did not show the rachitic changes usually observed in this disorder although they did suggest that there might be a generalised reduction in bone mineral density.

Both parents had alkaline phosphatase levels well within the normal range (typically low normal in heterozygote carriers of hypophosphatasia) and normal calcium concentrations (typically raised in hypocalciuric hypercalcaemia). The patient's investigations are summarised in table 1 . She was commenced on a low calcium diet, comprising less than $90 \mathrm{mg}$ calcium daily as well as chlorothiazide $(25 \mathrm{mg} / \mathrm{kg})$ to reduce urinary calcium excretion. Her calcium fell into the normal range (fig 1) and her alkaline phosphatase increased tol43 IU/l. Her urine calcium creatinine ratio also fell to more normal values.

She was started on lactulose and sodium picosulphate because of her constipation and maintained a daily to alternate day bowel habit on this regimen. Our patient remained hypotonic despite normalisation of calcium levels, and at subsequent assessments she was noted to be hyporeflexic with muscle wasting proximally in her upper limbs and proximally and distally in her lower limbs. At this stage she was noted to have developed a frog-like posture when supine, although she could still sit unaided. Other components of her development apart from motor function were normal and there were no feeding difficulties and no concerns about recurrent or severe respiratory tract infections. Creatine phosphokinase was checked on two separate occasions and was normal (69 and $54 \mathrm{U} / \mathrm{l}$ ), but in view of the clinical picture she was referred to the local muscle clinic. Molecular genetic testing revealed a homozygous deletion of SMN1 exons 7 and 8, which, in the context of the clinical picture, confirmed a diagnosis of spinal muscular atrophy type $2 .{ }^{56}$ Her current management includes regular physiotherapy with her dietary calcium intake titrated according to her blood and urine biochemistry.

\section{DISCUSSION}

This is the first time to our knowledge that an infant has developed hypercalcaemia and associated symptoms because of an underlying neuromuscular disorder. This is unlikely to be a chance association and the hypercalcaemia with hypercalciuria and nephrocalcinosis in this child probably reflects altered bone turnover as a consequence of reduced muscle tone and activity.

Hypercalcaemia is described in adolescents with neuropathy ${ }^{7}$ and immobilisation can also result in this biochemical picture. ${ }^{8}$ Patients with abnormal bone structure and function may be particularly susceptible. ${ }^{9}{ }^{10}$ We suspect that a "shift" in the balance between dietary intake, bone formation, and bone breakdown away from the norm was responsible for the biochemical picture that we observed with a relatively high calcium intake for a skeleton that was not growing and developing in the normal manner. Hypercalcaemia is a rare 


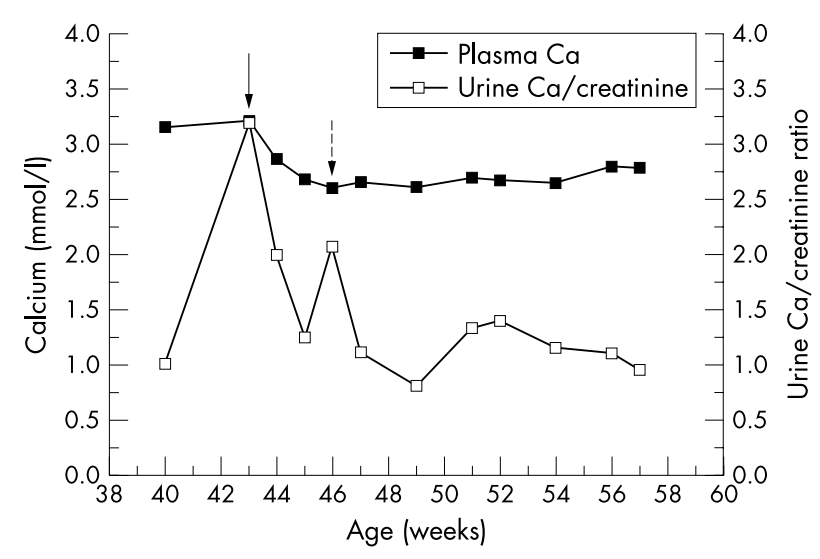

Figure 1 Total plasma calcium concentrations and urine calcium/ creatinine ratio plotted against age (weeks). The unbroken arrow illustrates when a low calcium diet was introduced and the broken arrow when chlorothiazide was commenced.

problem in infancy and childhood and we took care to exclude other causes of this biochemical picture in this age group.

The spinal muscular atrophies are a clinically and genetically heterogeneous group of disorders. They are characterised by degeneration of the spinal cord anterior horn cells and associated muscular atrophy and weakness. The subcategorisation of childhood proximal spinal muscular atrophy, which is caused by deletions of the SMN1 gene on chromosome 5, relies on the achievement or not of specific motor milestones. Children with type 1 spinal muscular atrophy typically present very early with hypotonia and never achieve the ability to sit independently. These children typically die of the complications of respiratory impairment by the age of 2 years. Spinal muscular atrophy type 2 is milder-children sit independently, often having normal motor milestones in the first 6-8 months, but subsequently do not walk unaided. While these children may be susceptible to complications such as chest infections and feeding difficulties, with appropriate management, survival into adulthood is likely. In type 3 spinal muscular atrophy, children do achieve the ability to walk independently; the spectrum of severity in this type of spinal muscular atrophy is very broad indeed.

Our patient had a low alkaline phosphatase level at presentation, which rose as circulating calcium concentrations fell on a low calcium diet. Hypercalcaemia can suppress PTH and inhibit bone formation and we were keen to encourage passive and active muscular activity as a means of enhancing bone accretion as the calcium fell. The subsequent rise in alkaline phosphatase is likely to reflect the beneficial impact of normocalcaemia and active and passive movement on bone formation.

Children with spinal muscular atrophy or congenital muscular dystrophy are frequently hypotonic in the first months of life, and this may be associated with constipation that is attributed to their underlying muscle weakness. We do not know the extent to which hypercalcaemia occurs in other
Table 1 Biochemistry at presentation

\begin{tabular}{lll}
\hline Biochemistry & Level & Normal values \\
\hline Calcium & $3.16 \mathrm{mmol} / \mathrm{l}$ & $(2.2-2.6 \mathrm{mmol} / \mathrm{l})$ \\
Phosphate & $1.8 \mathrm{mmol} / \mathrm{I}$ & $(1.4-2.4 \mathrm{mmol} / \mathrm{l})$ \\
Alkaline phosphatase (ALP) & $93 \mathrm{U} / \mathrm{I}$ & $(150-375)$ \\
Bone specific ALP & 42.0 & \\
PTH & $5 \mathrm{ng} / \mathrm{l}$ & $(10-65)$ \\
Bone ALP & $42 \mathrm{U} / \mathrm{I}$ & \\
Urine calcium/creatinine ratio & $1-3.2$ & $(<2)$ \\
Total vitamin D & $73 \mathrm{pmol} / /$ & $(10-50)$ \\
$1,25 \mathrm{OH}$ vitamin D & $21 \mathrm{pmol} / \mathrm{I}$ & $(20-120 \mathrm{pmol} / \mathrm{l})$ \\
Thyroid stimulating hormone & $3.1 \mathrm{mU} / \mathrm{I}$ & $(0.3-4.7)$ \\
Free thyroxine & 17 & $(11-23)$ \\
\hline & & \\
& & \\
\hline
\end{tabular}

young children with neuromuscular disease, although it is possible that inter-individual differences in bone metabolism might contribute to susceptibility. We believe that this as an area worthy of further study.

\section{ACKNOWLEDGEMENTS}

We would like to thank Professor Michael Whyte for his helpful comments about this patient prior to diagnosis.

\section{Authors' affiliations}

K Khawaja, S Watson, T Cheetham, Department of Paediatrics, Royal Victoria Infirmary, Newcastle upon Tyne NE1 4LP, UK

W T Houlsby, Children's Department, North Tyneside General Hospital, North Shields NE29 8NH, UK

K Bushby, Institute of Human Genetics, University of Newcastle upon Tyne NEI 3BZ, UK

Correspondence to: $\mathrm{Dr} T$ Cheetham, Senior lecturer in Paediatric Endocrinology, Children's Outpatients, Royal Victoria infirmary, Newcastle upon Tyne NE1 4LP, UK; t.d.cheetham@ncl.ac.uk

Accepted 18 June 2003

\section{REFERENCES}

1 Heath DA, Shaw NJ. Disorders of calcium and bone metabolism. In Brook CDG, Hindmarsh PC, eds. Clinical pediatric endocrinology. Oxford: Blackwell Science, 2001:390-410.

2 Pearce SHS, Trump D, Wooding C, et al. Calcium-sensing receptor mutations in familial benign hypercalcaemia and neonatal hyperparathyroidism. J Clin Invest 1995;96:2683-92.

3 Cronin CS, Reeve TS, Robinson B, et al. Primary hyperparathyroidism in childhood and adolescence. J Paediatr Child Health 1996;32:397-9.

4 Lowery MC, Morris CA, Ewart A, et al. Strong correlation of elastin deletions, detected by FISH, with Williams syndrome: evaluation of 235 patients. Am J Hum Genet 1995;57:49-53.

5 Gendron Nathalie H, Macekenzie Alex E. Spinal muscular atrophy: molecular pathology. Curr Opin Neurol 1999;12:137-42.

6 Talbot K. What's new in the molecular genetics of spinal muscular atrophy. Eur J Paediatr Neurol 1997;1:149-55.

7 Walls TJ, Ashworth B, Saunders M. Immobilisation hypercalcaemia complicating polyneuropathy in adolescent boys. I Neurolog Neurosurg Psychiatry 1984;47:1232-5

8 Dibble JB, Penney MD. Analysis of the components of the hypercalcaemia in a 14-year-old boy following prolonged immobilisation. Acta Paediatr Scand 1983;72:207-10.

9 Williams CJ, Smith RA, Ball RJ, et al. Hypercalcaemia in osteogenesis imperfecta treated with pamidronate. Arch Dis Child 1997;76:169-70.

10 Chines A, Petersen DJ, Schranck FW, et al. Hypercalciuria in children severely affected with osteogenesis imperfecta. J Pediatr 1991;119:51-7. 